\title{
In vitro investigation of the effects of exogenous sugammadex on coagulation in orthopedic surgical patients
}

\author{
II Ok Lee, Young Sung Kim, Hae Wone Chang ${ }^{*}$ (D), Heezoo Kim, Byung Gun Lim and Mido Lee
}

\begin{abstract}
Background: Previous studies have shown that sugammadex resulted in the prolongation of prothrombin time and activated partial thromboplastin time. In this study, we aimed to investigate the in vitro effects of exogenous sugammadex on the coagulation variables of whole blood in healthy patients who underwent orthopedic surgery.

Methods: The effects of sugammadex on coagulations were assessed using thromboelastography (TEG) in kaolin-activated citrated blood samples taken from 14 healthy patients who underwent orthopedic surgery. The in vitro effects of three different concentrations of sugammadex $\left(42,193\right.$, and $\left.301 \mu \mathrm{g} \mathrm{mL}{ }^{-1}\right)$ on the TEG profiles were compared with those of the control $\left(0 \mu \mathrm{g} \mathrm{mL}{ }^{-1}\right)$. Previous studies indicated that these exogenous concentrations correspond to the approximate maximum plasma concentrations achieved after the administration of 4,16 , and $32 \mathrm{mg} \mathrm{kg}^{-1}$ sugammadex to healthy subjects.
\end{abstract}

Results: Increased sugammadex concentrations were significantly associated with reduced coagulation, as evidenced by increases in reaction time ( $r$ ), coagulation time, and time to maximum rate of thrombus generation (TMRTG), and decreases in the angle, maximum amplitude, and maximum rate of thrombus generation. Compared with the control, the median percentage change (interquartile range) in the TEG values of the samples treated with the highest exogenous sugammadex concentration was the greatest for $r, 53 \%(26,67.3 \%)$, and TMRTG, 48\% (26, 59\%).

Conclusions: This in vitro study suggests that supratherapeutic doses of exogenous sugammadex might be associated with moderate hypocoagulation in the whole blood of healthy subjects.

Trial registration: identifier: UMIN000029081, registered 11 September 2017.

Keywords: Blood coagulation, Sugammadex, Thromboelastography

\section{Background}

Sugammadex (Bridion ${ }^{\circ}$, Merck Sharp \& Dohme B.V., Haarlem, The Netherlands), a modified gamma-cyclodextrin, forms a stable complex with steroidal neuromuscular blockers via internal lipophilic bonds. The resultant hydrophilic encapsulated compound does not bind to proteins or the plasma membrane and is eliminated unchanged in the urine [1]. De Kalm and co-workers reported that sugammadex caused a moderate (11-22\%) increase in the prothrombin time (PT) and activated partial thromboplastin time (aPTT) in healthy volunteers after doses of 16 and

* Correspondence: chelenh@gmail.com

Department of Anesthesiology and Pain Medicine, Korea University Guro

Hospital, Korea University College of Medicine, Seoul, Republic of Korea
$4 \mathrm{mg} \mathrm{kg}^{-1}[2,3]$. In vitro experiments suggest that sugammadex may inhibit the effects of factor $\mathrm{Xa}$ on prothrombin-to-thrombin conversion in the common pathway of coagulation and may inhibit factor Xa formation via the intrinsic pathway [2].

Thromboelastography (TEG) provides a real-time viscoelastic profile of patients, from the initial thrombin activation to fibrinolysis, and yields information not available through conventional coagulation studies. TEG is also used as a tool to assess the anticoagulation action of oral anticoagulant drugs [4] and to assist in clinical decisions for patients taking oral anticoagulants requiring urgent surgery $[5,6]$. The evaluation of the potential

(c) The Author(s). 2018 Open Access This article is distributed under the terms of the Creative Commons Attribution 4.0 International License (http://creativecommons.org/licenses/by/4.0/), which permits unrestricted use, distribution, and 
effects of drugs on coagulation variables is important because a combination of more than two drugs that affect coagulation may substantially increase a patient's risk of bleeding [7].

In this study, we aimed to use TEG to assess the effects of exogenous sugammadex on the coagulation variables of whole blood taken from healthy patients undergoing elective orthopedic surgery.

\section{Methods}

This study was approved by the institutional review board at Korea University Guro Hospital, Seoul, Korea, in 2017 (protocol: KUGH17171-001) and registered with UMIN Clinical Trials Registry (identifier: UMIN000029081). After approval from the ethics committee and obtaining informed consent from the patients, we enrolled 15 healthy subjects, aged between 19 and 45 years, with American Society of Anesthesiologists (ASA) physical status score of 1 or 2, who were undergoing elective orthopedic surgery. Patients who had received aspirin or oral anticoagulants within 14 days of the study, who showed abnormal coagulation laboratory values (platelet count $<100,000, \mathrm{PT}$-international normalised ratio $(\mathrm{PT}-\mathrm{INR})>1.5$, or $\mathrm{aPTT}>50 \mathrm{~s}$ ), pregnant women, patients with liver or renal disease, patients with other surgical history within 30 days of the study, and patients taking oral contraceptives were excluded. Blood samples were collected prior to anesthetic induction. An 18-gauge peripheral IV cannula was inserted into the antecubital vein and an initial blood sample was obtained for TEG analysis under minimal stasis with a tourniquet by using the two-syringe technique. The first $4 \mathrm{~mL}$ of blood was discarded to avoid tissue contamination. The next $5.4 \mathrm{~mL}$ of blood was collected using a $10 \mathrm{~mL}$ syringe, and the blood was transferred into two $2.7 \mathrm{~mL}$ tubes, each containing $0.5 \mathrm{~mL}$ of $0.109 \mathrm{M}$ buffered sodium citrate (Vacutainer; Becton, Dickinson and Company, Franklin Lakes, NJ, USA). The collected blood samples were immediately mixed gently 5-6 times, incubated for approximately 15-20 min, and then analyzed. Briefly, $1 \mathrm{~mL}$ of citrated blood was added into a vial containing kaolin. Then, $52 \mu \mathrm{L}$ of exogenous sugammadex was mixed with $948 \mu \mathrm{L}$ of $0.9 \%$ saline to yield a $2.4 \mathrm{mM}$ solution of sugammadex. For each patient, one solution of citrated whole blood and three solutions of citrated whole blood mixed with different concentrations of exogenous sugammadex were prepared in separate kaolin vials using micropipettes, as follows:

Control: $1 \mathrm{~mL}$ of citrated whole blood or sugammadex solutions at each of the three concentrations.

Citrated whole blood (1 mL) with $42 \quad \mu g$ of sugammadex: final exogenous sugammadex concentration $=42 \mu \mathrm{g} \mathrm{mL} \mathrm{m}^{-1}$.

Citrated whole blood $(1 \mathrm{~mL})$ with $199 \mu \mathrm{g}$ of sugammadex: final exogenous sugammadex concentration $=193 \mu \mathrm{g} \mathrm{mL}^{-1}$.
Citrated whole blood $(1 \mathrm{~mL})$ with $319 \mu \mathrm{g}$ of sugammadex: final exogenous sugammadex concentration $=301 \mu \mathrm{g} \mathrm{mL} \mathrm{m}^{-1}$.

We selected the three concentrations of exogenous sugammadex as those that corresponded to the approximate maximum mean plasma concentrations achieved after the administration of 4,16 , and $32 \mathrm{mg} \mathrm{kg}^{-1}$ sugammadex to healthy patients in a previous study $[7,8]$. Doses of 4 and $16 \mathrm{mg} \mathrm{kg}^{-1}$ are used for the reversal of deep neuromuscular block (when recovery has reached at least 1-2 post-tetanic counts) and the immediate reversal after the administration of rocuronium $1.2 \mathrm{mg} \mathrm{kg}^{-1}$ within $3 \mathrm{~min}$, respectively, and $32 \mathrm{mg} \mathrm{kg}^{-1}$ is a supratherapeutic safe dose for awake patients after the use of rocuronium $1.2 \mathrm{mg} \mathrm{kg}^{-1}$ [9]. At the highest concentration, the volume of sugammadex solution was less than $6 \%$ of the whole blood volume.

After mixing 8-10 times by inversion, $340 \mu \mathrm{L}$ of kaolin-activated blood from each solution was pipetted into a plastic cup in a TEG 5000 hemostasis analyser pre-warmed to $37{ }^{\circ} \mathrm{C}$ (Haemonetics, Braintree, USA). Each sample was recalcified in a plastic cup through the addition of $20 \mu \mathrm{L} 0.2 \mathrm{M} \mathrm{CaCl}_{2}$, and a TEG analysis was performed within 1 min after the samples were reconstituted. Additional venous blood was also obtained to assess baseline values for hematologic and coagulation data (Table 1). PT and aPTT were measured using the STAR Evolution (Diagnostica stago, Parsippany, New Jersey). An abnormal aPTT was defined as a clotting time outside our laboratory's normal range (30.2-42.4 s). Prolonged PT was defined as a clot time greater than 14.4 s (normal range: 11.3-14.4 s).

The variables recorded included the reaction time (r, min), which represented the rate of clot initiation, the coagulation

Table 1 Patient characteristics and a summary of hematological and coagulation variables. The data are presented as the mean (SD) or number of patients

\begin{tabular}{ll}
\hline & $(n=14)$ \\
\hline Age $(\mathrm{y})$ & $32(9)$ \\
Sex (M/F) & $11 / 3$ \\
Body weight (kg) & $83.1(18.1)$ \\
Height (cm) & $171.5(8.2)$ \\
$\mathrm{HB}^{\mathrm{a}}\left(\mathrm{g} \cdot \mathrm{dL}^{-1}\right)$ & $15.0(1.2)$ \\
$\mathrm{Hct}^{\mathrm{b}}(\%)$ & $44.2(3.6)$ \\
$\mathrm{Cr}^{\mathrm{c}}\left(\mathrm{mg} \cdot \mathrm{dL}^{-1}\right)$ & $0.8(0.2)$ \\
$\mathrm{PT}^{\mathrm{d}}(\%)$ & $106.7(11.2)$ \\
$\mathrm{PTINR}^{\mathrm{e}}$ & $0.97(0.06)$ \\
aPTT $^{\mathrm{f}}(\mathrm{s})$ & $35.2(4.8)$ \\
Platelet $\left(10^{3} \cdot \mathrm{HL}^{-1}\right)$ & $256(66.7)$ \\
\hline
\end{tabular}

${ }^{\mathrm{a}} \mathrm{HB}$, hemoglobin; ${ }^{\mathrm{b}} \mathrm{Hct}$, hematocrit; ${ }^{\mathrm{c}} \mathrm{Cr}$, creatinine; ${ }^{\mathrm{d}} \mathrm{PT}$, prothrombin time; ${ }^{\mathrm{e} P \mathrm{~T}}$ INR, prothrombin time internalization normalization ratio; ${ }^{\mathrm{f}} \mathrm{PTT}$, activated prothrombin time 
time ( $\mathrm{k}, \mathrm{min})$, and the angle ( $\alpha$, degrees), which represented the rate of fibrin polymerization. The maximum amplitude (MA, mm) represented the maximum clot strength and was depicted as the greatest width of the TEG tracing. The shear elastic modulus strength ( $\mathrm{G}$, dynes $\mathrm{cm}^{-2}$ ) is a parametric measure of clot firmness expressed in metric units and calculated from the MA according to the following equation: $\mathrm{G}=(5000 \times \mathrm{MA}) /(100-\mathrm{MA})$. Lysis 30 (Ly30) is an index of fibrinolytic activity.

In addition to conventional TEG parameters, we measured clot kinetic parameters using a graph produced by TEG. These parameters included the maximum rate of thrombus generation (MRTG, dynes $\mathrm{cm}^{-2} \mathrm{~s}$ ), which is the first derivative of the velocity of the increase in clot strength, which starts from the increase in G and ends at the stabilization of the clot strength. In addition, we determined the time to maximum clot strength (TMRTG, min), which is the time necessary to reach the MRTG and reflects the enzymatic contribution to clot formation. Total thrombin generation (TTG), which is the total positive area under the velocity curve, represents the total change in elastic resistance until clot strength stabilization, and depicts thrombin generation.

The TEG was determined by an observer blinded to the group assignment and sampling time. The primary outcomes were the TEG parameters for citrated whole blood and citrated whole blood mixed with exogenous sugammadex, while the secondary outcome was the association between the sugammadex concentration and changes in TEG parameters.

We assessed the $r$ values of the plain whole citrated blood and whole citrated blood containing $42 \mu \mathrm{g} \mathrm{mL} \mathrm{m}^{-1}$ sugammadex in an initial pilot sample of five patients undergoing orthopedic surgery. The mean $r$ values were $5.3 \pm 0.9$ and $6 \pm 1.2$. Student's paired $t$-test revealed that the coefficient of correlation was 0.94 with a power of 1.49; therefore, to reach a power of $95 \%$ and an alpha level of 0.01 , the estimated sample size was 11 . We enrolled 15 patients to avoid any possible technical difficulties associated with blood sampling or TEG analysis. The data were assessed for normality by using normality plots and the Kolmogorov-Smirnov test. Changes in individual TEG parameters were assessed by a repeated-measures analysis of variance with Holm-Sidak's multiple comparison tests. We also performed a mixed model regression analysis for each TEG parameter to evaluate the association between the concentration of exogenous sugammadex and thromboelastographic parameters. The percentage change was calculated for each TEG parameter for all groups. Statistical analyses were conducted using GraphPad Prism version 7.03 for Windows (GraphPad Inc., La Jolla, USA) and Predictive Analytics Software (PASW) statistics 18.0 (SPSS Inc., Chicago, IL, USA). Values of $P<0.05$ were considered statistically significant.

\section{Results}

Blood samples were obtained from 15 patients with ASA physical status 1-2 who underwent orthopedic surgery. One sample was excluded owing to a technical error in blood sampling that may have affected the values of the TEG parameters. Therefore, the results were analyzed for 14 patients. The demographic and baseline laboratory hematological data of all patients are presented in Table 1.

The TEG parameters and the dynamic parameters are shown in Table 2. The values for the $\mathrm{r}$ time, $\mathrm{k}$ time, $\alpha$ angle, MA, G, MRTG, and TMRTG in the control group were within the normal range. Only TTG results were above the normal values. There was a significant increase in $r$ time and TMRTG at all tested concentrations of sugammadex and the values were within or above the normal range. There were statistically significant differences in all TEG parameters between the control and the $301 \mu \mathrm{g} \mathrm{mL}{ }^{-1}$ concentration of sugammadex. There were no statistically significant differences between the 301 and $193 \mu \mathrm{g} \mathrm{mL} \mathrm{m}^{-1}$ concentrations of sugammadex.

The average median (interquartile range) and mean (SD) percentage difference between the control and the highest concentration of sugammadex were as follows: $\mathrm{r}$ time $=53 \%$ $(26,67.3 \%), \mathrm{k}$ time $=39.5 \%(18.8,61 \%), \alpha$ angle $=-11.7 \%$ $(16.9 \%), \quad \mathrm{MA}=-10.5 \% \quad(-21,-2.5 \%), \quad \mathrm{MRTG}=-22.6 \%$ $(20.7 \%)$, TMRTG $=48 \%(26,59 \%)$, and $\mathrm{TTG}=-9.5 \%$ $(-20.3,-2.5 \%)$. Figure 1 shows the relationship between the $\%$ difference in $\mathrm{r}$ time from the control and sugammadex concentrations across the volunteers.

The mixed model regression analysis indicated that an increase in sugammadex concentration was significantly associated with increases in $\mathrm{r}$ time, $\mathrm{k}$ time, and TMRTG, and with decreases in $\alpha$ angle, MA, G, Ly30, MRTG, and TTG $(P<0.05$, respectively) (Table 3$)$.

\section{Discussion}

This study was conducted to investigate the effects of exogenous sugammadex on TEG parameters. The two highest concentrations of sugammadex (198 and $301 \mu \mathrm{g} \mathrm{mL} \mathrm{m}^{-1}$ ) significantly altered all TEG parameters. However, at the therapeutic concentration $\left(42 \mu \mathrm{g} \mathrm{mL}^{-1}\right)$, sugammadex did not induce clinically meaningful changes in any parameters. The $r$ time, $\alpha$ angle, and TMRTG level were significantly different between the lowest and the two highest concentrations of sugammadex, which was indicative of a dose-dependent response. Previous investigations have shown that the anticoagulation effects of sugammadex measured by conventional coagulation tests occurred at similar magnitudes in in vivo and in vitro studies, with dose-dependent effects observed [2]. The highest concentration of sugammadex increased the $\mathrm{r}$ time by more than $50 \%$ compared with the control. In this study, we found direct associations 
Table 2 Thromboelastographic parameters from citrated whole blood and citrated whole blood treated with exogenous sugammadex $\left(42,193\right.$, and $\left.301 \mathrm{\mu g} \mathrm{mL}^{-1}\right)$ collected from patients who underwent orthopedic surgery

\begin{tabular}{|c|c|c|c|c|c|}
\hline & Exogenous & dex concentrat & & & \\
\hline & 0 & 42 & 193 & 301 & $P$ \\
\hline $\begin{array}{l}R^{a}(\min ) \\
2-8\end{array}$ & $5.6(1.2)$ & $6.3(1.5)^{* * *}$ & $7.9(1.9)^{\diamond \diamond \diamond, * * * *}$ & $8.2(2.4)^{* * * *}$ & $<0.0001$ \\
\hline $\begin{array}{l}K^{b}(\min ) \\
1-3\end{array}$ & $1.7(0.4)$ & $1.8(0.5)$ & $2.3(0.7)^{\diamond_{, *}^{*}}$ & $2.5(1.2)^{\square,}{ }^{*}$ & 0.0018 \\
\hline $\begin{array}{l}\text { Angle } e^{c} \text { (degrees) } \\
55-78\end{array}$ & $64.5(8.6)$ & $64.8(6.7)$ & $54.0(10.9)^{\diamond}, *$ & $56.5(10.8)^{\square, *}$ & 0.0004 \\
\hline $\begin{array}{l}M A^{d}(\min ) \\
51-69\end{array}$ & $67.9(6.8)$ & $64.8(6.0)^{*}$ & $61.8(8.0)^{*}$ & $60.5(8.9)^{\square, ~ * *}$ & 0.0008 \\
\hline $\begin{array}{l}\mathrm{G}^{\mathrm{e}}\left(\text { dynes }\left(\mathrm{cm}^{2}\right)^{-1}\right) \\
4.6-10.9 \mathrm{~K}\end{array}$ & $11.3(4.0)$ & $9.6(2.5)$ & $8.7(2.9)$ & $8.3(3.1)^{*}$ & 0.0065 \\
\hline $\begin{array}{l}\text { Ly30 (\%) } \\
0-8\end{array}$ & $1.1(1.0)$ & $1.3(1.0)$ & $0.9(1.1)$ & $0.3(0.5)^{\square,,^{*}}$ & 0.0461 \\
\hline $\begin{array}{l}\operatorname{MRTG}^{9}\left(\mathrm{~mm} \mathrm{~min}^{-1}\right) \\
5-17\end{array}$ & $12.7(3.3)$ & $11.8(3.0)$ & $10.3(3.4)^{*}$ & $9.9(3.7)^{* *}$ & 0.0021 \\
\hline $\begin{array}{l}\text { TMRTG }^{\mathrm{h}}(\mathrm{min}) \\
6-12\end{array}$ & $7.0(1.5)$ & $7.7(1.7)^{* *}$ & $9.5(2.3)^{\diamond \diamond \diamond, * * *}$ & $10.0(2.9)^{\square \square, * * *}$ & $<0.0001$ \\
\hline $\begin{array}{l}\text { TTG }\left(\mathrm{mm} \mathrm{min}^{-1}\right) \\
584-796\end{array}$ & $821(83.1)$ & $781.2(70.3)^{*}$ & $749.7(97.0)^{*}$ & $733.7(106.2)^{* *}$ & 0.0010 \\
\hline
\end{tabular}

The values presented are the mean (SD), $n=14$. Holm-Sidak's multiple comparisons test was performed to compare the significance of the differences between each study solution. ${ }^{\mathrm{a}} \mathrm{R}$, reaction time to clot formation; ${ }^{\mathrm{b}} \mathrm{K}$, time to achieve a clot strength of $20 \mathrm{~mm}$ amplitude; ${ }^{\mathrm{c} A n g l e}$, rate of clot growth; ${ }^{\mathrm{d}} \mathrm{MA}$, maximum amplitude of clot strength; ${ }^{\mathrm{e}} \mathrm{G}$, shear elastic modulus strength; ${ }^{9} \mathrm{MRTG}$, maximum rate of thrombus generation; ${ }^{\mathrm{h}} \mathrm{TMRTG}$, time to maximum rate of thrombus generation; 'TTG, total thrombin time; Statistically significant differences between; (301 vs 193), $\square$ (301 vs 42), $\diamond(193$ vs 42) and * (control). Single symbol and * indicate $P<0.05$ compared with control value; two symbols $\square \square$ and ${ }^{* *}$ indicate $P<0.01$; and three symbols $\square \square \square, \diamond \diamond \diamond$, and ${ }^{* * *}$ indicate $P<0.001$,

**** indicate $P<0.0001$

between the estimated concentration of sugammadex in vitro and all individual TEG parameters by using previously reported mixed-effects modelling methods [10]. The changes in all parameters indicated modest anticoagulant action. The observation of reduced fibrinolysis in the two higher concentrations of sugammadex was an unexpected finding, and the underlying mechanism is unknown. However, all values were within the normal range, and we did not perform another test for fibrinolysis in our patients. Therefore, clinical relevance is limited

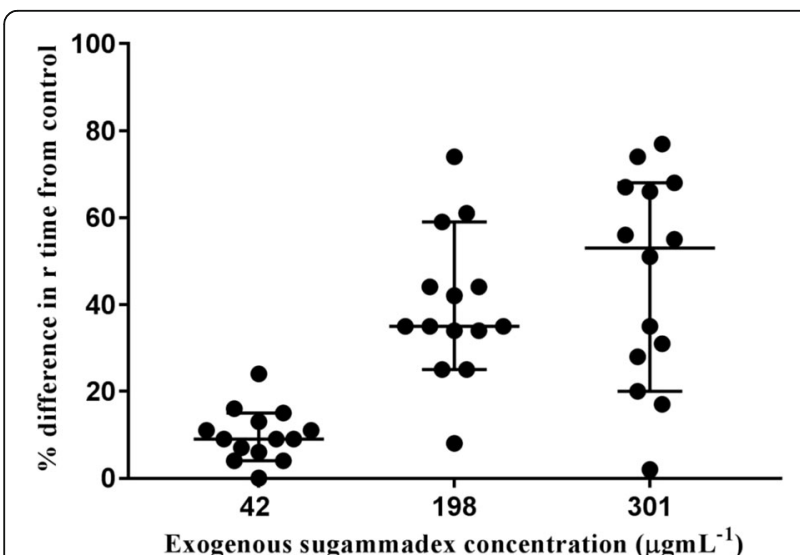

Fig. 1 The relationship between the $r$ time \% difference from control and the concentration of exogenous sugammadex
Table 3 Linear mixed-effects regression model for the effect of exogenous sugammadex on thromboelastographic parameters

\begin{tabular}{|c|c|c|c|}
\hline & Intercept & $\beta$ coefficient (standard error) & $P$ value \\
\hline $\begin{array}{l}R^{a}(\min ) \\
2-8\end{array}$ & 5.9 & $0.008(0.002)$ & 0.002 \\
\hline $\begin{array}{l}\mathrm{K}^{\mathrm{b}}(\mathrm{min}) \\
1-3\end{array}$ & 1.7 & $0.003(0.001)$ & 0.018 \\
\hline $\begin{array}{l}\text { Angle (degrees) } \\
55-78\end{array}$ & 64.5 & $-0.032(0.011)$ & 0.009 \\
\hline $\begin{array}{l}M^{d}(\min ) \\
51-69\end{array}$ & 66.7 & $-0.021(0.009)$ & 0.028 \\
\hline $\begin{array}{l}\mathrm{G}^{\mathrm{e}}\left(\text { dynes }\left(\mathrm{cm}^{2}\right)^{-1}\right) \\
4.6-10.9 \mathrm{~K}\end{array}$ & 10.6 & $-0.008(0.003)$ & 0.024 \\
\hline $\begin{array}{l}\operatorname{Ly} 30(\%) \\
0-8\end{array}$ & 1.3 & $-0.003(0.001)$ & 0.010 \\
\hline $\begin{array}{l}\operatorname{MRTG}_{5-17}\left(\mathrm{~mm} \mathrm{~min}^{-1}\right) \\
\end{array}$ & 12.3 & $-0.009(0.004)$ & 0.036 \\
\hline $\begin{array}{l}\text { TMRTGh (min) } \\
6-12\end{array}$ & 7.2 & $0.010(0.003)$ & 0.002 \\
\hline $\begin{array}{l}\text { TTG' }\left(\mathrm{mm} \mathrm{min}^{-1}\right) \\
584-796\end{array}$ & 805.8 & $-0.246(0.108)$ & 0.033 \\
\hline
\end{tabular}

The average baseline $r$ time calculated using mixed model repeated linear regression was $5.9 \mathrm{~min}$; the rate of change of $r$ time was $0.008 \mathrm{~min}$ per $1 \mu \mathrm{g} \mathrm{m}^{-1}$ increase in exogenous sugammadex concentration. ${ }^{\mathrm{a}} \mathrm{R}$, reaction time to clot formation; ${ }^{\mathrm{b}} \mathrm{K}$, time to achieve a clot strength of $20 \mathrm{~mm}$ amplitude; ${ }^{\mathrm{C}}$ Angle, rate of clot growth; ${ }^{\mathrm{d}} \mathrm{MA}$, maximum amplitude of clot strength; ${ }^{e} \mathrm{G}$, shear elastic modulus strength; ${ }^{\mathrm{M} M R T G}$, maximum rate of thrombus generation; ${ }^{\mathrm{h}} \mathrm{TMRTG}$, time to maximum rate of thrombus generation; 'TTG, total thrombin time 
for this finding. We expected that an increase in sugammadex concentration in the whole blood by $10 \mu \mathrm{g} \mathrm{mL}-1$ would result in an increase in the $\mathrm{r}$ time by $4.8 \mathrm{~s}$ and suggested that coagulation might be compromised when the blood concentration of sugammadex exceeded $500 \mu \mathrm{g} \mathrm{mL}^{-1}$, which corresponded to an increase in the $\mathrm{r}$ value of $>10 \mathrm{~min}$. This blood concentration could be expected after administration of a sugammadex dose $>32 \mathrm{mg} \mathrm{kg}^{-1}$. Our findings are in accordance with the results of the recent clinical in vivo ROTEM study. By using $\mathrm{INTEM}^{\bullet}$ (thromboelastometry assay using egallic acid, phospholipid, and calcium), Carron and co-workers showed that each $100 \mathrm{mg}$ increase in sugammadex dose increased the clotting time by approximately $5.2 \mathrm{~s}$ in morbidly obese patients [11]. In the in vitro ROTEM study, Dirkmann and colleagues showed an increase in the INTEM $^{\circ}$ and EXTEM $^{\bullet}$ (thromboelastometric assay using tissue factor, phospholipid, and calcium chloride) clotting times and a decrease in the activity of the intrinsic pathway-associated factors (VIII, IX, XI, and XII) [12]. However, they suggested that the affinity of sugammadex for phospholipid binding might interfere with the results of various coagulation studies that use phospholipids. The mechanism responsible for the anticoagulant effects of sugammadex is not clear. De Calm and co-workers suggested that the anticoagulant effects were related to the inhibition and induction of the activity of the intrinsic pathway-associated factor (Xa) [2]. The changes in the TEG parameters observed in the present study were similar to those reported in a previous in vitro study that used oral direct factor $\mathrm{Xa}$ inhibitors and direct anti-thrombin inhibitors [4]. $\mathrm{R}$ time, $\mathrm{k}$ time, $\alpha$ angle, MRTG, and TMRTG were statistically different in factor $\mathrm{Xa}$ inhibitor or direct thrombin inhibitors when compared with the control. Pipilis and co-workers found that among 75 patients with atrial fibrillation, those with high plasma dabigatran concentrations exhibited an $\mathrm{r}$ time $>11 \mathrm{~min}$ and an aPTT $>65 \mathrm{~s}$, with a correlation between the $r$ time and aPTT [5]. In patients receiving warfarin, TEG and ROTEM showed an acceptable diagnostic value [13]; in addition, the PT-INR and TEG $r$ times correlated with thrombin generation and were corrected after prothrombin complex administration in patients with intracranial bleeding who were treated with warfarin [14]. Therefore, TEG may offer a valuable tool for the assessment of the effectiveness of the management of perioperative bleeding in patients receiving warfarin or direct oral anticoagulants. Moreover, it may provide coagulation profiles for patients undergoing non-elective surgery who have recently received anticoagulant therapy.

Additionally, patients who are actively bleeding and/or have altered hemostasis are expected to be admitted to the ICU and may need point of care viscoelastic testing as well as other laboratory exams. Delayed weaning from mechanical ventilation would be a more appropriate choice until the establishment of adequate transfusion, the correction of acidosis and hypothermia, and other supportive treatments for coagulation abnormalities.

Our study has several limitations. First, it is an in vitro study; therefore, the extent to which the results can be translated into the clinical setting is limited. However, as sugammadex is not metabolized after IV injection, our results may be reasonably extrapolated to in vivo effects. Furthermore, in the clinical scenario, the $r$ time is usually shortened, while the increase or decrease of the $\alpha$ angle and MA by mild hemodilution depends on whether native or citrated blood is used $[15,16]$. Therefore, the expected changes related to the clinical dose of sugammadex may not be easily detected by using in vivo TEG in surgical patients. Postoperative hypercoagulability, due to a decrease in anti-thrombin after surgery, might reduce the magnitude of the changes in coagulation parameters induced by sugammadex [17]. In an observational study of cancer surgery and other minor surgeries, PT and aPTT were not altered with sugammadex use $[18,19]$. Second, we used citrated blood for a practical reason: the TEG analysis of all samples could not be performed within 4 min of the collection of blood samples. The use of citrated blood in TEG analysis could yield different results from those measured in samples of native, non-citrated blood [20].

\section{Conclusions}

Based on the finding of this in vitro study, a whole blood sugammadex concentration above $193 \mu \mathrm{g} \mathrm{mL}^{-1}$ would enhance hypocoagulability on thromboelastography of patients without coagulation abnormality. Future clinical studies are needed to examine the effects of sugammadex on the coagulation profiles of patients with altered hemostasis and, importantly, to examine outcomes related to sugammadex exposure related to enhanced hypocoagulablilty.

\section{Abbreviations \\ ASA: American Society of Anesthesiologists; G: shear elastic modulus strength; k: coagulation time; Ly 30: lysis 30; MA: maximum amplitude; MRTG: Maximum rate thrombus generation; r: reaction time; \\ TEG: Thromboelastography; TMRTG: Time to maximum rate thrombus generation; TTG: Total thrombus generation; a: angle}

\section{Funding}

This study was supported by internal funding from the anesthetic department at Korea University Guro Hospital.

Availability of data and materials

The datasets used and/or analysed during the current study are available from the corresponding author on reasonable request. 


\section{Authors' contributions}

IO analyzed and interpreted the data and prepared the manuscript. YS performed the statistical analysis of the data. HW conceived of the study design, conducted the study, analyzed and interpreted the data, and wrote the manuscript. $\mathrm{HZ}$ was consulted on all aspects of the research BG provided professional supervision. MD conducted the study. All authors read and approved the final manuscript.

\section{Ethics approval and consent to participate}

This study was approved by the institutional review board at Korea University Guro Hospital, Seoul, Korea, in 2017 (protocol: KUGH17171-001). Written informed consent was obtained from all patients.

\section{Competing interests}

The authors declare that they have no competing interests.

\section{Publisher's Note}

Springer Nature remains neutral with regard to jurisdictional claims in published maps and institutional affiliations.

Received: 29 November 2017 Accepted: 10 May 2018

\section{Published online: 24 May 2018}

\section{References}

1. Saokham P, Loftsson T. Y-Cyclodextrin. Int J Pharm. 2017;516:278-92.

2. De Kam PJ, Grobara P, Prohn M, Hoppener F, Kluft C, Burggraaf J, et al. Effects of sugammadex on activated partial thromboplastin time and prothrombin time in healthy subjects. Int J Clin Pharmacol Ther. 2014; 52:227-36.

3. de Kam PJ, El Galta R, Kruithof AC, Fennema H, van Lierop MJ, Mihara K, et al. No clinically relevant interaction between sugammadex and aspirin on platelet aggregation and coagulation parameters. Int J Clin Pharmacol Ther. 2013;51:976-85.

4. Dias JD, Norem K, Doorneweerd DD, Thurer RL, Popovsky MA, Omert LA. Use of thromboelastography (TEG) for detection of new oral anticoagulants. Arch Pathol Lab Med. 2015;139:665-73.

5. Pipilis A, Makrygiannis S, Anagnostou G, Kaliampakos S, Tsakonas G, Sourlas $\mathrm{N}$, et al. Dabigatran plasma levels, aPTT and thromboelastography in patients with AF: implications for allowing early non-elective surgical procedures. J Thromb Thrombolysis. 2017;44:9-13.

6. Neyens R, Bohm N, Cearley M, Andrews C, Chalela J. Dabigatran-associated subdural hemorrhage: using thromboelastography (TEG((R))) to guide decision-making. J Thromb Thrombolysis. 2014;37:80-3.

7. Davidson BL, Verheijen S, Lensing AW, Gebel M, Brighton TA, Lyons RM, et al. Bleeding risk of patients with acute venous thromboembolism taking nonsteroidal anti-inflammatory drugs or aspirin. JAMA Intern Med. 2014;174:947-53.

8. de Kam PJ, van Kuijk J, Prohn M, Thomsen T, Peeters P. Effects of sugammadex doses up to $32 \mathrm{mg} / \mathrm{kg}$ alone or in combination with rocuronium or vecuronium on QTc prolongation: a thorough QTc study. Clin Drug Investig. 2010;30:599-611.

9. de Kam PJ, Hou J, Wang Z, Lin WH, van den Heuvel M. Pharmacokinetics of sugammadex $16 \mathrm{mg} / \mathrm{kg}$ in healthy Chinese volunteers. Int J Clin Pharmacol Ther. 2015;53:456-61.

10. Butwick A, Harter $S$. An in vitro investigation of the coagulation effects of exogenous oxytocin using thromboelastography in healthy parturients. Anesth Analg. 2011;113:323-6.

11. Carron M, Bertini D, Prandini T, Fanton F, Foletto M, Ori C, et al. Effect of sugammadex on coagulation as detected by rotational thromboelastometry in morbidly obese patients. Minerva Anestesiol. 2018;84:178-88.

12. Dirkmann D, Britten MW, Pauling H, Weidle J, Volbracht L, Gorlinger K, et al. Anticoagulant effect of sugammadex: just an in vitro artifact. Anesthesiology. 2016;124:1277-85.

13. Schmidt $D E$, Holmström $M$, Majeed A, Näslin D, Wallén $H$, Ågren A. Detection of elevated INR by thromboelastometry and thromboelastography in warfarin treated patients and healthy controls. Thromb Res. 2015;135:1007-11.

14. Voils SA, Martin EJ, Mohammed BM, Bayrlee A, Brophy DF. Laboratory assessment of warfarin reversal with global coagulation tests versus international normalized ratio in patients with intracranial bleeding. Blood Coagul Fibrinolysis. 2015;26:443-7.
15. Tuman KJ, Spiess BD, McCarthy RJ, Ivankovich AD. Effects of progressive blood loss on coagulation as measured by thrombelastography. Anesth Analg. 1987;66:856-63.

16. Kretschmer V, Daraktchiev A, Karger R. Does haemodilution produce a hypercoagulable state? Thromb Haemost. 2004;92:670-1.

17. Rahe-Meyer N, Fennema H, Schulman S, Klimscha W, Przemeck M, Blobner $M$, et al. Effect of reversal of neuromuscular blockade with sugammadex versus usual care on bleeding risk in a randomized study of surgical patients. Anesthesiology. 2014;121:969-77.

18. Raft J, Guerci P, Harter V, Fuchs-Buder T, Meistelman C. Biological evaluation of the effect of sugammadex on hemostasis and bleeding. Korean $\mathrm{J}$ Anesthesiol. 2015;68:17-21.

19. Tas N, Korkmaz H, Yağan Ö, Korkmaz M. Effect of sugammadex on postoperative bleeding and coagulation parameters after septoplasty: a randomized prospective study. Med Sci Monit. 2015;21:2382-6.

20. Roeloffzen $W W$, Kluin-Nelemans HC, Mulder AB, Veeger NJ, Bosman L, de Wolf JT. In normal controls, both age and gender affect coagulability as measured by thrombelastography. Anesth Analg. 2010;110:987-94.

\section{Ready to submit your research? Choose BMC and benefit from:}

- fast, convenient online submission

- thorough peer review by experienced researchers in your field

- rapid publication on acceptance

- support for research data, including large and complex data types

- gold Open Access which fosters wider collaboration and increased citations

- maximum visibility for your research: over $100 \mathrm{M}$ website views per year

At BMC, research is always in progress.

Learn more biomedcentral.com/submissions 